\title{
Distribuição de abundância de Talitroides topitotum (Burt) (Crustacea, Amphipoda, Talitridae) na área de entorno da Usina Hidroelétrica de Guaricana, Serra do Mar, Guaratuba, Paraná, Brasil ${ }^{1}$
}

\author{
Odete Lopez Lopes ${ }^{2} \&$ Setuko Masunari ${ }^{3}$ \\ ${ }^{1}$ Contribuição número 1418 do Departamento de Zoologia, Universidade Federal do Paraná. \\ ${ }^{2}$ Museu de História Natural Capão da Imbuia. Rua Benedito Conceição 407, 82810-080 Curitiba, Paraná, Brasil. \\ E-mail: odetellopes@yahoo.com.br \\ ${ }^{3}$ Departamento de Zoologia, Universidade Federal do Paraná. Caixa Postal 19020, 81531-980 Curitiba, Paraná, Brasil. \\ E-mail:setmas@ufpr.br
}

\begin{abstract}
Distribution of abundance of Talitroides topitotum (Burt) (Crustacea, Amphipoda, Talitridae) nearby the Guaricana Hydroeletric Plant, Serra do Mar, Guaratuba, Paraná. A study of distribution of abundance was carried out with the terrestrial amphipod Talitroides topitotum (Burt, 1934) from Serra do Mar, in the municipality of Guaratuba, Paraná State, Brazil. Monthly, collections were made with Malaise nets, from June/1985 to June/1986 at eight sites with varied degree of preservation, all located in a Tropical Rain Forest nearby the Guaricana Hydroeletric Plant. Four sites were located at $270 \mathrm{~m}$ of altitude and another four at $720 \mathrm{~m}$ high. Each collection period lasted five days. The precipitation rate oscillated from $43.70 \mathrm{~mm}$ to $388.30 \mathrm{~mm}$, the air temperature from $9.00^{\circ} \mathrm{C}$ to $37.50^{\circ} \mathrm{C}$ and the relative humidity of the air from $72.75 \%$ to $93.07 \%$. A total of 2191 amphipods were obtained, among which 1626 females with oostegits but without eggs in the marsupium, 558 ovigerous females, six juveniles and an adut without any secundary sexual characters. The capture was selective towards adult amphipod. The number of amphipod oscillated from 19 to 969 in the collection sites, with high frequencies in sites of intermediate degree of preservation. The annual frequency varied from six to 498 individuals. The $270 \mathrm{~m}$ high population showed four picks in the abundance curve, while in the $720 \mathrm{~m}$ high population only three. Antropological influence favoured high frequencies of amphipods, but in sites of excessive degree, these animals were less numerous. The conjuction between high precipitation and high relative humidity of the air favoured abundance of amphipod populations. On the other hand, they were limited by air temperatures below $13^{\circ} \mathrm{C}$ and above $35^{\circ} \mathrm{C}$.
\end{abstract}

KEY WORDS. Annual fluctuation, anthropological influences, Malaise trap, terrestrial amphipod.

RESUMO. Um estudo de distribuição de abundância foi realizado com o anfípodo terrestre Talitroides topitotum (Burt, 1934) na Serra do Mar, no município de Guaratuba, Paraná, Brasil. Coletas mensais, foram realizadas com redes de Malaise, de junho/1985 a junho/1986, em oito estações com graus variados de preservação, localizadas numa Floresta Tropical Ombrófila Densa na área de entorno da Usina Hidroelétrica de Guaricana. Quatro estações de coleta foram estabelecidas a $270 \mathrm{~m}$ de altitude e outras quatro a $720 \mathrm{~m}$. O período de amostragem foi de cinco dias. A precipitação oscilou de $43,70 \mathrm{~mm}$ a $388,30 \mathrm{~mm}$, a temperatura do ar de $9,00^{\circ} \mathrm{C}$ a $37,50^{\circ} \mathrm{C}$ e a umidade relativa do ar de $72,75 \%$ a $93,07 \%$. Um total de 2191 anfípodos foi obtido, sendo 1626 fêmeas com oostegitos mas sem ovos no marsúpio, 558 fêmeas ovígeras, seis juvenis e um adulto sem caracteres sexuais secundários. A captura foi seletiva para anfípodos adultos. O número de anfípodos oscilou de 19 a 969 nos locais amostrados, com altas freqüências em locais com grau intermediário de preservação. A frequiência anual variou de seis a 498 indivíduos. A população à $270 \mathrm{~m}$ de altitude mostrou quatro picos na curva de abundância, enquanto que a de $720 \mathrm{~m}$ mostrou apenas três. Influências antrópicas favoreceram altas freqüências de anfípodos, porém, em locais de alto grau, eles foram menos numerosos. A conjunção da alta precipitação e da elevada umidade relativa do ar favoreceu a população de anfípodos. Por outro lado, eles foram limitados por temperaturas do ar abaixo de $13^{\circ} \mathrm{C}$ e acima de $35^{\circ} \mathrm{C}$.

PALAVRAS CHAVE. Anfípodo terrestre, flutuação anual, influências antrópicas, redes de Malaise. 
Dentre os Amphipoda Gammaridea, somente a família Talitridae contém representantes adaptados à vida terrestre ou semiterrestre (Bousfield 1982). Os anfípodos terrestres são componentes da dieta de pássaros, onicóforos e planárias terrestres (Friend \& RichaRdson 1986). Eles contribuem diretamente para o processo de decomposição e para o metabolismo da serapilheira e sua presença eleva as taxas de respiração do solo, provavelmente em decorrência dos efeitos físicos de sua locomoção, que provocam afastamento das estruturas do solo e da própria serapilheira (FRIEND \& RichARDSON 1986).

Bousfield (1982), estudando as características ecológicosistemáticas e comportamentais da família Talitridae, com pouco mais de 200 espécies conhecidas, considerou que Talitrus decoratus Carl, 1934, Talitrus sylvaticus Shoemaker, 1963, Talitrus sylvaticus Bousfield, 1975, Talitrus (Talitroides) pacificus Hurley, 1955 e Talitrus (Talitropsis) topitotum Burt, 1934, são sinônimas de Talitroides topitotum (Burt, 1934), a espécie alvo deste estudo.

Talitroides topitotum ocorre em regiões tropicais, sub-tropicais e de clima temperado quente, bem como em estufas botânicas na Europa e América do Norte. Tem citação para o Sri Lanka, local de sua descrição (BurT 1934), continente e ilhas oceânicas da Índia, região australiana, ilhas do Pacífico (Marquesas, Havaí e Hong Kong), continente europeu e ilhas do Oceano Atlântico (Alemanha, Reino Unido, Açores e Madeira) (Friend \& Richardson 1986). Na América do Norte, ocorre nos Estados Unidos (Califórnia, Louisiana e Carolina do Sul) (Biernbaum 1980), e no México (Alvarez et al. 2000); na América do Sul ocorre no Brasil (Paraná, Rio de Janeiro, São Paulo) (Lemos de Castro 1972, Lemos de Castro \& Pereira 1978, S.R. MALKowsKi comunicação pessoal). A ocorrência em nosso país provavelmente deve-se à importação de plantas dos Estados Unidos (Ulian \& Mendes 1987) onde se propagaram a partir de eucaliptos e outras plantas importadas da Austrália (Bousfield 1960). Nos dois locais, as populações de T. topitotum tornaramse gradualmente numerosas em jardins, quintais e até mesmo em florestas (Ulian \& Mendes 1987).

A biologia dos Talitridae foi revisada por Friend \& RichaRdSOn (1986), sendo que a biologia de T. topitotum foi alvo dos estudos de Biernbaum (1980), Lam \& MA (1989), Richardson (1992) e Alvarez et al. (2000). A fisiologia dos Talitridae foi estudada por MORRITT (1998), entretanto a fisiologia e o comportamento desta espécie foram estudadas sob condições de laboratório, por Mendes \& Ulian (1987) e Ulian \& Mendes (1987, 1988). Um estudo de distribuição altitudinal de T. topitotum foi realizado por RichARDSON (1992).Os únicos estudos sobre populações de T. topitotum foram realizados nas cidades de Hong Kong por Lam \& Ma (1989) e do México por Alvarez et al. (2000).

O objetivo do presente trabalho é descrever a distribuição de abundância de Talitroides topitotum em oito estações de coleta na Serra do Mar, na área de entorno da Usina Hidroelétrica de Guaricana em relação à altitude, e analisar a distribuição da abundância de quatro estações localizadas a $270 \mathrm{~m}$ de altitude em relação à pluviosidade, temperatura do ar e umidade relativa do ar.

\section{MATERIAL E MÉTODOS}

\section{Área de estudo}

O estudo foi realizado na área de entorno do complexo da Usina Hidroelétrica de Guaricana que compreende a usina propriamente dita e uma represa. A usina está localizada na Serra dos Castelhanos, sudoeste da Serra do Mar paranaense $\left(25^{\circ} 45^{\prime} \mathrm{S}\right.$ e $\left.48^{\circ} 55^{\prime} \mathrm{W}\right)$, no município de Guaratuba, e a Represa de Guaricana a 5,7 km de distância, no município de São José dos Pinhais. A área de 812,14 ha é administrada pela Companhia Paranaense de Energia Elétrica - COPEL (Fig 1).

A topografia do local é bastante acidentada. A região é coberta por vegetação densa e exuberante com características de Floresta Ombrófila Densa, apresentando índices de umidade relativa do ar e densidade pluviométrica elevados (S.R. MALKOWSKI comunicação pessoal).

A usina (22.500 kW - COPEL) está localizada a uma altitude de $270 \mathrm{~m}$ acima do nível do mar. Nas proximidades dela há uma vila onde residem os trabalhadores da região. A vegetação que crescia originalmente no entorno da usina e da vila era de Floresta Ombrófila Densa Baixo Montana (Rizzins 1979, IBGE 1992), porém atualmente, a área se mostra bastante impactada pela ação antrópica, seja pela urbanização como pela construção de rodovias de acesso, seja pelo loteamento em chácaras particulares.

A represa, a uma altitude de $720 \mathrm{~m}$ acima do mar, é formada pelas águas do Rio Arraial. A cobertura vegetal é de Floresta Ombrófila Densa Montana que apresenta saturação de água na superfície e chuvas copiosas e regulares (Rızzinı 1979). A vegeteção, bem preservada, está submetida a uma ação antrópica mais amena, constituída apenas pela via de acesso à usina hidroelétrica.

$\mathrm{Na}$ área de estudo foram estabelecidas oito estações de coleta: quatro estações (A, B, C e D) nas imediações da usina e da vila, a $270 \mathrm{~m}$ de altitude e quatro (E, F, G e H) na área da represa a $720 \mathrm{~m}$ de altitude (Fig. 2).

As distâncias entre as estações de coleta a $270 \mathrm{~m}$ foram 147,0 m (entre A e B), 1.195,6 m (entre B e C) e 294,0 m (entre C e D), tomadas linearmente. As estações A e B estão localizadas à margem esquerda do Rio Arraial, em meio à mata ciliar, $\mathrm{e}$ próximas à estrada de acesso à usina e à vila. As estações $\mathrm{C} \mathrm{e} \mathrm{D}$ localizam-se dentro de uma chácara de propriedade particular; o ponto C está em meio a vegetação de Cecropia pachystachya Trécul - embaúba e de Secchium edule Steud. - chuchu, o que segundo classificação do IBGE (1992), caracteriza capoeirão em fase intermediária de recuperação, enquanto que a estação D, segundo a mesma classificação, se encontra em meio à floresta secundária em fase adiantada de recuperação.

As estações E, F, G e H (a 720 m de altitude) localizam-se em meio à vegetação bem preservada, distantes entre si de 495,5 m (entre E e F), 630,0 m (entre F e G) e 776,5 m (entre G e H). A estação $\mathrm{E}$ foi estabelecida à margem de uma mata, a $\mathrm{F}$ em meio à capoeira, a $\mathrm{G}$ dentro da mata e a $\mathrm{H}$ próximo à encosta, ao lado da rodovia de acesso à usina e à vila.

Revista Brasileira de Zoologia 21 (2): 219-227, junho 2004 


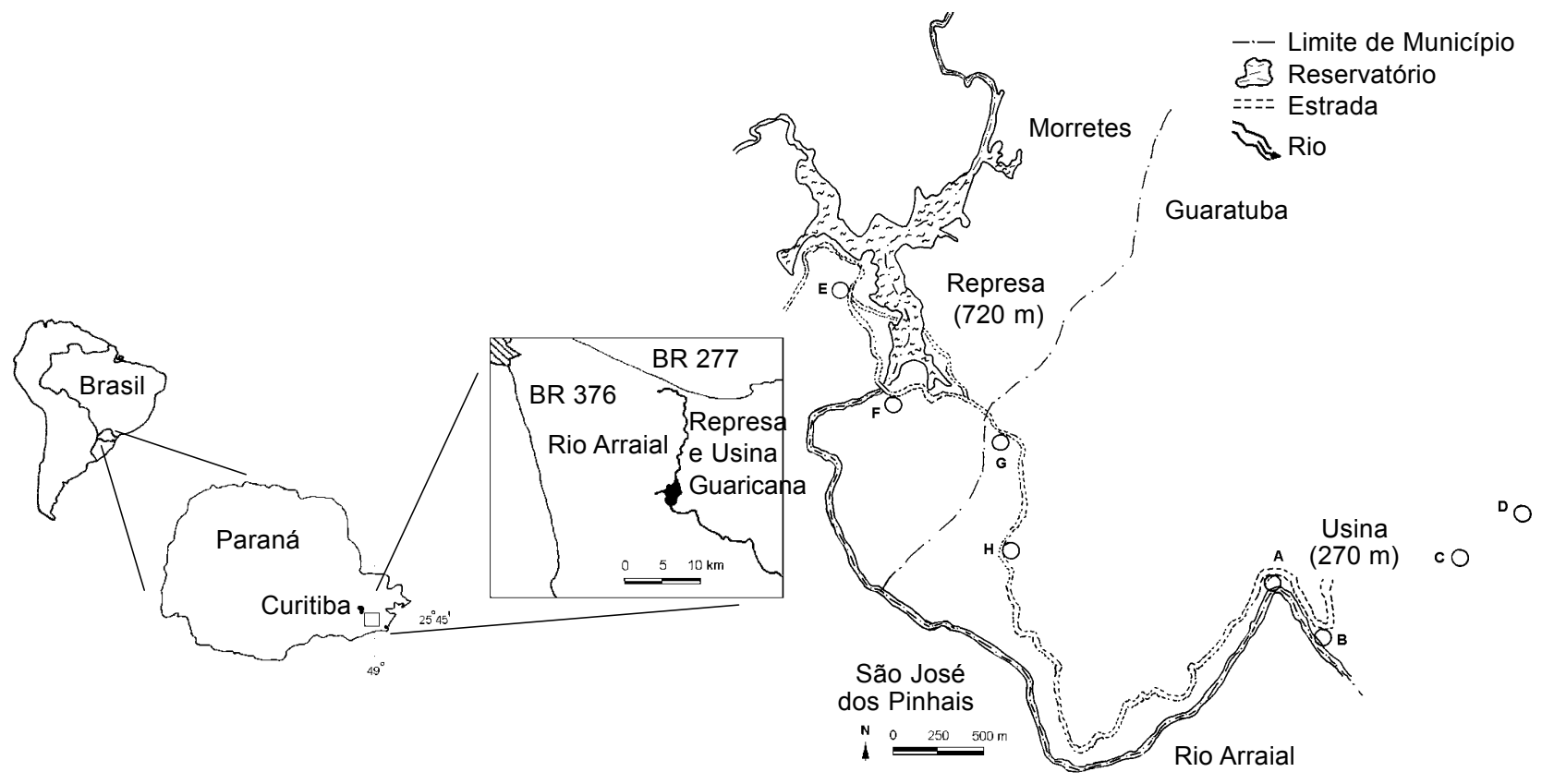

Figuras 1-2. (1) Localização da Usina Hidroelétrica de Guaricana, Guaratuba, Paraná, Brasil; (2) Localização das estações de coleta. As estações A, B, C e D estão a 270 m de altitude; E, F, G e H estão a 720 m de altitude.

\section{Métodos}

As coletas foram realizadas em intervalos que variaram de 20 a 42 dias nas seguintes datas: de 24 a 28 de junho/1985, 22 a 26 de julho/1985, 02 a 06 de setembro/1985, 30 de setembro a 04 de outubro/1985, 21 a 25 de outubro/1985, 25 a 29 de novembro/1985, 16 a 20 de dezembro/1985, 27 a 31 de janeiro/1986, 24 a 28 de fevereiro/1986, 17 a 21 de março/1986, 28 de abril a 02 de maio/1986 e de 02 a 06 de junho/1986. Cada coleta compreendeu um período de cinco dias e foi considerada mensal. Devido à variação nos intervalos, não houve coleta em agosto/1985, porém, houve duas em setembro/1985; da mesma forma, os dois dias de maio/1986 em que ocorreram coletas foram considerados como parte do período de coleta correspondente ao mês de abril.

As variáveis abióticas foram registradas apenas na altitude de $270 \mathrm{~m}$, e portanto a sua flutuação relacionada apenas aos dados bióticos das estações de coleta A, B, C e D. Os valores diários do índice pluviométrico foram fornecidos pela COPEL e foram registrados às 7:00 e às 17:00 h; os valores de abril/ 1986 foram parciais e os de maio e junho/1986 não foram medidos. As médias mensais do índice pluviométrico obtidas na Usina Hidroelétrica de Guaricana, no período compreendido entre 1958 e 1996, foram fornecidas pela COPEL. Os valores de umidade relativa do ar (\%) e de temperatura do ar $\left({ }^{\circ} \mathrm{C}\right)$ foram registrados durante todos os dias de coleta; as temperaturas, máxima e mínima, e a umidade relativa do ar foram medidas diariamente no início da manhã, ao meio-dia e ao final da tarde de cada coleta.
Os animais foram coletados em todas as coletas, utilizando-se redes tipo Malaise como artefato de captura, sendo colocada uma armadilha em cada uma das estações de coleta. As armadilhas foram montadas durante a manhã do primeiro dia e retiradas a partir do meio-dia do quinto dia de coleta, quando todo o material fixado foi retirado, totalizando um esforço de 576 horas. O meio de preservação utilizado foi álcool etílico a 70\%. Todo o material biológico enconta-se depositado na Coleção de Crustacea do Museu de História Natural Capão da Imbuia.

O nível de antropia foi estabelecido arbitrariamente conforme a intensidade da influência humana nas estações de coleta, de grau um "*” em área menos impactada, a grau quatro “****” em local mais impactado. Desta forma, as estações D “*” e E “**” estão sujeitas a menor influência humana e são caracterizadas por uma vegetação bem preservada. A estação E sofre apenas com a influência pela passagem de veículos; as A "****", B “****" e H “****” são as mais impactadas pela proximidade da usina e da vila, com circulação intensa de pessoas e veículos; F “***” e G “***”, são impactadas pela circulação de veículos e a estação $C$ “***”, está localizada em área agrícola desativada em fase de recuperação.

No laboratório, sob microscópio estereoscópico, as fêmeas foram identificadas pela presença de oostegitos, as fêmeas ovígeras, pela presença de ovos no marsúpio e os juvenis, pela ausência de caracteres secundários. Um exemplar com o comprimento total do corpo semelhante ao dos exemplares adultos não apresentou oostegitos ou setas peniais.

Revista Brasileira de Zoologia 21 (2): 219-227, junho 2004 
Análisou-se a correlação entre as variáveis abióticas entre si e entre elas e a abundância nas estações de coleta A, B, C e D através da correlação de Pearson, com um nível de confiança de $95 \%$. Nas análises foram utilizados os valores totais de pluviosidade ocorridos nos dias de coleta e o total mensal; foram ainda utilizados os valores médios, medidos durante as coletas, da umidade relativa do ar e das temperaturas do ar, no período de estudo. As temperaturas máxima e mínima do ar em cada um dos meses foram tomadas a partir dos valores absolutos medidos em cada coleta.

Para estabelecer possíveis padrões de semelhança entre as estações de coleta, foram realizados teste de Friedman e análise de agrupamento a partir das distâncias euclidianas entre as freqüências absolutas das oito estações, utilizando-se o programa Statistica, versão 5.1.

\section{RESULTADOS}

A pluviosidade total registrada entre junho/1985 e março/1986 foi de 1794,50 mm, com uma média mensal de 179,45 $\mathrm{mm}$. Em janeiro/1986 houve a maior pluviosidade total (Fig. 3) com 388,30 mm, seguido por fevereiro do mesmo ano, com $257,40 \mathrm{~mm}$, enquanto que as menores ocorreram durante $\mathrm{o}$ ano de 1985, em junho com 47,90 mm e em julho com 43,70 mm. Acompanhando a tendência dos meses, a pluviosidade ocorrida durante os dias de coleta totalizou 127,40 mm em janeiro/ 1986, 6,80 mm em julho/1985 e foi nula em junho/1985 (Fig. 3). Os valores de pluviosidade de março/1986 foram de 3,50 $\mathrm{mm}$, em contraste com o valor mensal de $212,60 \mathrm{~mm}$, indicando que a coleta ocorreu em dias atípicos do mês. De uma forma geral, a oscilação anual da precipitação medida nos cinco dias de coleta mensal seguiu o padrão da total mensal (Fig. 3).

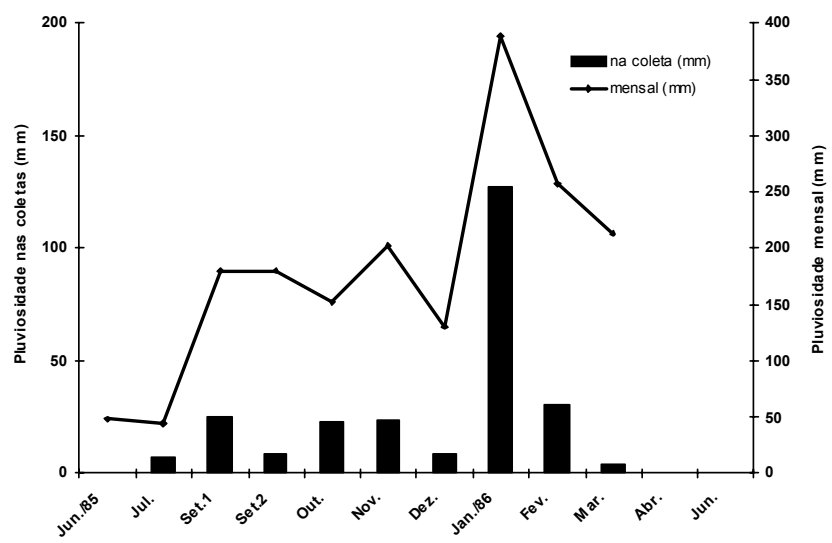

Figura 3. Usina de Guaricana. Pluviosidade total mensal (linha) e nos cinco dias de coleta (barras), no período de estudo.

A umidade relativa do ar foi maior durante a manhã (8:00 h) e à noite $(19: 00 \mathrm{~h})$, quando esteve acima dos $80 \%$, e foi menor próximo ao meio-dia. Durante todos as coletas, o ar manteve-se com umidade relativa alta, sempre acima dos 70\% (Fig. 4); a máxima ocorreu no início de setembro/1985 quando chegou a $93,0 \%$ e a mínima em dezembro deste mesmo ano com 74,04\%. Embora em janeiro/1986 tenha registrado um valor excepcionalmente alto de pluviosidade, a umidade relativa foi apenas um dos valores mais altos e não o mais alto. A umidade relativa do ar mostrou-se pouco correlacionada com a pluviosidade entretanto, o baixo teor de umidade relativa registrado em dezembro/1985 pode estar relacionado ao baixo índice pluviométrico observado neste mês.

A temperatura máxima mensal do ar verificada foi de $37,50^{\circ} \mathrm{C}$ em fevereiro/ 1986 e esteve sempre acima de $27,0^{\circ} \mathrm{C}$ do final de setembro/1985 a março/1986 (Fig. 4). As temperaturas mínimas mensais foram registradas em junho/1986 $\left(9,0^{\circ} \mathrm{C}\right)$ e no início de setembro/1985 $\left(9,5^{\circ} \mathrm{C}\right)$. A temperatura média mensal oscilou de $13,75^{\circ} \mathrm{C}$ no início de setembro/1985 a $27,0^{\circ} \mathrm{C}$ em fevereiro/1986 (Fig. 4). De uma forma geral, os meses de verão mostraram as mais altas temperaturas médias (acima de $23^{\circ} \mathrm{C}$ ) e as de inverno, as mais baixas (abaixo de $15^{\circ} \mathrm{C}$ de julho a início de setembro/1985); temperaturas médias em torno de $20^{\circ} \mathrm{C}$ foram registradas nos meses de outono e primavera (Fig. 4).

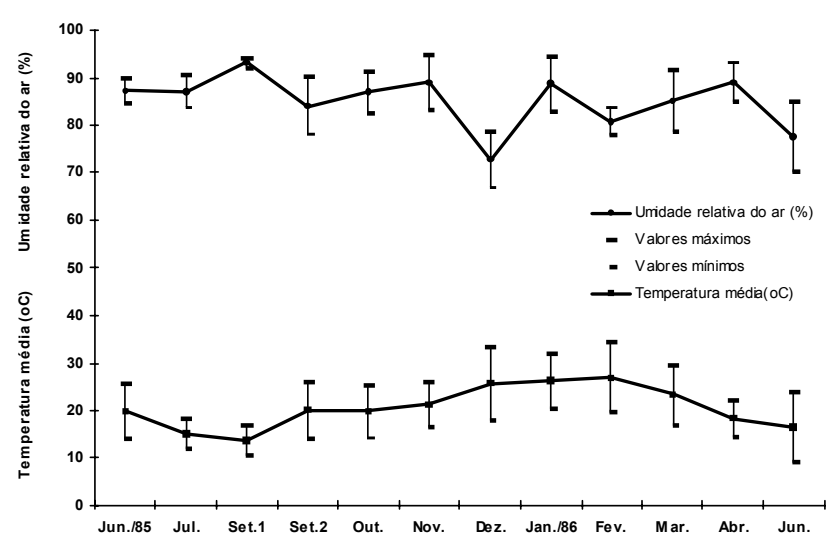

Figura 4. Usina de Guaricana. Flutuação anual média da umidade relativa e da temperatura do ar, medidas durante os cinco dias de coleta em cada mês de estudo. Estão indicados os valores máximos e mínimos de cada uma das variáveis.

A pluviosidade total mensal se mostra correlacionada com a temperatura mínima média na coleta $(r=0,75, p<0,05)$. Para os valores medidos na coleta, a umidade relativa do ar mostrase correlacionada de forma negativa com a temperatura máxima $(r=-0,70, p<0,05)$.

Foram coletados 2191 anfípodos, sendo 1626 fêmeas com oostegitos, mas, sem ovos no marsúpio, 558 fêmeas ovígeras e

Revista Brasileira de Zoologia 21 (2): 219-227, junho 2004 
seis juvenis (Tab. I); um exemplar com comprimento total do corpo de $7,30 \mathrm{~mm}$, correspondente a um adulto nesta população, não apresentou nem oostegitos nem setas peniais. Nas estações A, B, C e D, à altitude de 270 m, foram capturados 755 exemplares, dos quais 545 fêmeas, 207 fêmeas ovígeras, 2 juvenis e 1 exemplar de sexo indefinido; nas estações E, F, G e H, à altitude de $720 \mathrm{~m}$, foram capturados 1436 exemplares, com 1081 fêmeas, 351 fêmeas ovígeras e 4 juvenis.

A estação de coleta $E$ apresentou a maior freqüência absoluta, com 969 exemplares, e a estação A, com 19 exemplares, foi a que apresentou a menor freqüência. As estações $C, F, G$ e $\mathrm{H}$ apresentaram freqüências similares, variando de 199 exemplares na estação C a 133 na estação H (Tab. I).

A menor freqüência de anfípodos ocorreu na estação A,

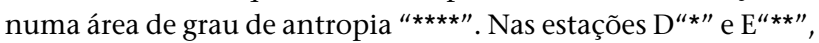

foram observadas as maiores freqüências: 453 e 969 exemplares, respectivamente (Tab. I). Naqueles de índices “***”, os valores foram intermediários. As oscilações reforçam a importância da presença humana para a propagação desta espécie exótica, tanto à altitude de $720 \mathrm{~m}$ como à de $270 \mathrm{~m}$, porém sugerem a necessidade de uma serapilheira com certa exuberância e localizada em local bem preservado para o aumento da abundância.

No teste de Friedman, as médias das abundâncias não se mostraram significativamente diferentes entre as estações estudadas (Fig. 5). Por outro lado, a análise de agrupamento a partir das distâncias euclidianas das abundâncias semelhantes entre as várias estações de coleta (Fig. 6) possibilitou a visualização de três grupos: um formado pela estação E, outro pela estação D e o último constituído pelas demais.

Tabela I. Talitroides topitotum. Freqüência absoluta de exemplares nas estações de coleta. Entre parênteses o grau de antropia: $\left({ }^{*}\right)$ imperceptível, $\left(^{* *}\right)$ pouco evidente, $\left(^{* * *}\right)$ evidente, $\left(^{* * * *}\right)$ elevado.

\begin{tabular}{|c|c|c|c|c|c|c|c|c|c|c|c|c|c|c|}
\hline \multirow{2}{*}{$\begin{array}{c}\text { Estações } \\
\text { (Grau de antropia) }\end{array}$} & \multirow{2}{*}{$\begin{array}{c}\text { Estágio de } \\
\text { desenvolvimento e sexo }\end{array}$} & \multicolumn{7}{|c|}{1985} & \multicolumn{5}{|c|}{1986} & \multirow{2}{*}{ Total } \\
\hline & & Jun & Jul & Set1 & Set 2 & Out & Nov & Dez & Jan & Fev & Mar & Abr & Jun & \\
\hline \multirow[t]{2}{*}{$A(* \star \star *)$} & Fêmea & & 2 & & & 9 & 1 & & 2 & & 1 & 1 & & 16 \\
\hline & Fêmea ovígera & & & & & 1 & & & 1 & & & 1 & & 3 \\
\hline \multirow[t]{3}{*}{$B(* * * *)$} & Fêmea & & 41 & & & 3 & & & 4 & 17 & 5 & & & 70 \\
\hline & Fêmea ovígera & & 8 & & & & & & & 3 & 1 & 1 & & 13 \\
\hline & Juvenil & & 1 & & & & & & & & & & & 1 \\
\hline \multirow[t]{2}{*}{$C(* * *)$} & Fêmea & & & 12 & 85 & & 9 & 3 & 4 & 1 & 32 & & & 146 \\
\hline & Fêmea ovígera & & & 1 & 28 & & 2 & 2 & & 2 & 18 & & & 53 \\
\hline \multirow[t]{4}{*}{$\mathrm{D}\left({ }^{*}\right)$} & Fêmea & & & & 3 & 63 & & & 143 & 21 & 78 & & 5 & 313 \\
\hline & Fêmea ovígera & & 2 & & & 48 & & & 51 & 3 & 32 & & 2 & 138 \\
\hline & Juvenil & & & & & & & & & 1 & & & & 1 \\
\hline & Sem caracteres sexuais & & & & & & & & & 1 & & & & 1 \\
\hline \multirow[t]{2}{*}{$E(* *)$} & Fêmea & 160 & & 43 & 97 & 66 & 6 & & 2 & 84 & 135 & 163 & & 756 \\
\hline & Fêmea ovígera & 6 & & 1 & 8 & 19 & 2 & & 2 & 23 & 98 & 54 & & 213 \\
\hline \multirow[t]{2}{*}{$\mathrm{F}(* * *)$} & Fêmea & & & & 3 & 10 & 4 & & 25 & 16 & 2 & 54 & & 114 \\
\hline & Fêmea ovígera & & & & & 6 & 1 & & 18 & 10 & 1 & 21 & & 57 \\
\hline \multirow[t]{3}{*}{$G(* * \star)$} & Fêmea & 4 & 16 & & & & & 1 & 16 & & 35 & 6 & 20 & 98 \\
\hline & Fêmea ovígera & & & & & & & & 21 & & 38 & 2 & & 61 \\
\hline & Juvenil & & & & & & & & & & 4 & & & 4 \\
\hline \multirow[t]{2}{*}{$H(* * *)$} & Fêmea & 2 & 14 & 1 & & 17 & 2 & & 10 & 13 & 13 & 40 & 1 & 113 \\
\hline & Fêmea ovígera & 1 & 1 & & & & & & 5 & 4 & 5 & 4 & & 20 \\
\hline \multirow[t]{4}{*}{ Freqüência absoluta } & Fêmea & 166 & 73 & 56 & 188 & 168 & 22 & 4 & 206 & 152 & 301 & 264 & 26 & 1626 \\
\hline & Fêmea ovígera & 7 & 11 & 2 & 36 & 74 & 5 & 2 & 98 & 45 & 193 & 83 & 2 & 558 \\
\hline & Juvenil & 0 & 1 & 0 & 0 & 0 & 0 & 0 & 0 & 1 & 4 & 0 & 0 & 6 \\
\hline & Sem caracteres sexuais & 0 & 0 & 0 & 0 & 0 & 0 & 0 & 0 & 1 & 0 & 0 & 0 & 1 \\
\hline Abundância anual & & 173 & 85 & 58 & 224 & 242 & 27 & 6 & 304 & 199 & 498 & 347 & 28 & 2191 \\
\hline
\end{tabular}



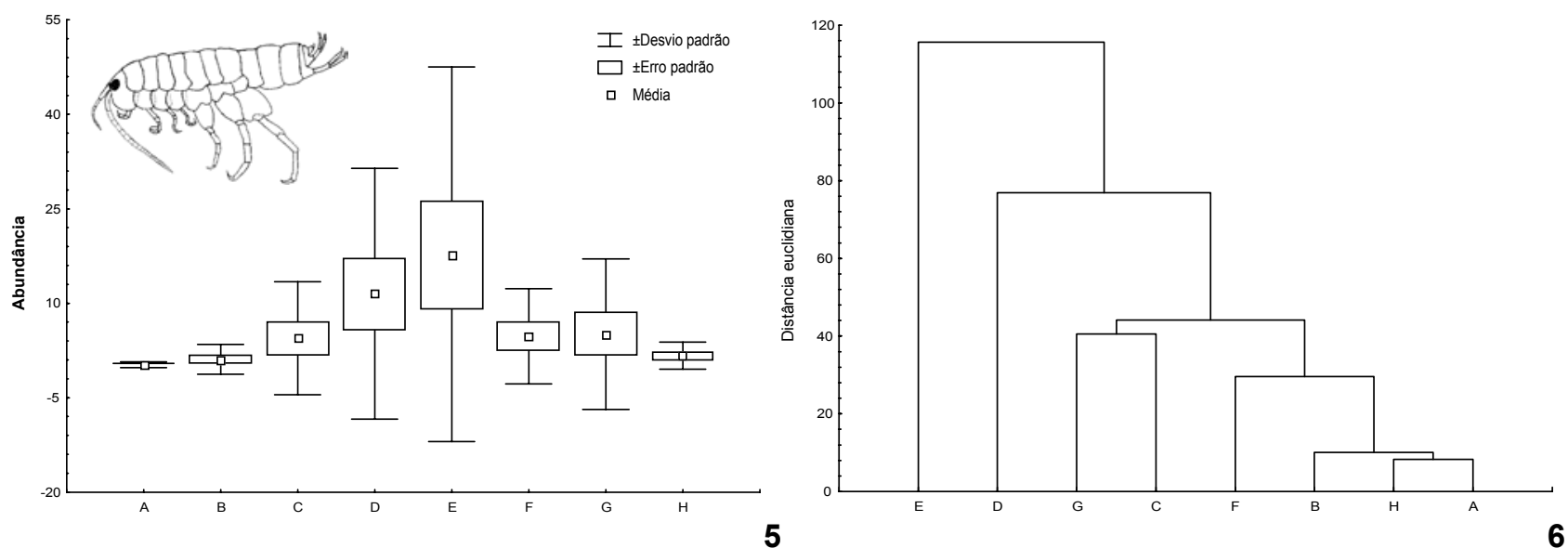

Figuras 5-6. Talitroides topitotum. (5) Médias em cada estação de coleta, durante o período de estudo. As linhas indicam o desvio padrão e os retângulos o erro padrão. O desvio padrão é teórico. (6) Análise de agrupamento das abundâncias em cada estação de coleta, a partir das distâncias euclidianas, durante o período de estudo.

A amplitude de variação anual de freqüência absoluta foi de seis (dezembro/1985) a 498 indivíduos (março/1986), com três picos de ocorrência (Fig. 7, Tab. I). O primeiro, de junho/1985 a início de setembro/1985 registrou abundância decrescente, pois 173 exemplares foram registrados em junho/ 1985 e 58 exemplares no início de setembro/1985; este pico provavelmente iniciou no primeiro semestre de 1985 e observamos apenas parte dele durante o período de estudo. O segundo pico foi de setembro/1985 a dezembro deste mesmo ano; o ponto máximo ocorreu em outubro/1985 com 242 exemplares. O terceiro pico ocorreu de janeiro/1986 a junho/1986, com dois pontos máximos, um em janeiro/1986 com 304 exemplares e outro em março/1986 com 498 exemplares. A oscilação da abundância acompanhou de modo geral a flutuação da umidade relativa do ar durante o período (Figs 4 e 7). A temperatura do ar parece ter sido o fator regulador no início de setembro/1985, quando o valor médio da temperatura ficou abaixo $\operatorname{dos} 15^{\circ} \mathrm{C}$.

A abundância, na altitude de $270 \mathrm{~m}$, acompanhou a abundância geral e os menores valores ocorreram no inverno e no verão (Fig. 7, Tab. I), quando a abundância foi nula em junho/ 1985, sete em junho/1986 e cinco em dezembro/1985. O primeiro pico ocorreu de junho/1985 a início de setembro/1985, atingindo o ponto máximo em julho/1985 com 54 exemplares. O segundo, de setembro/1985 a dezembro/1985, com máximo em outubro/1985 com 124 exemplares. O terceiro pico, de janeiro/1986 a abril/1986, não ficou bem definido e pareceu haver superposição de gerações pois dois valores máximos ficaram evidentes: um em janeiro/1986, com 205 exemplares, e outro em março/1986, com 167 exemplares. A partir de junho/1986 parece ter havido a formação de um novo pico, o que se constituiria na formação de um quarto pico no período.

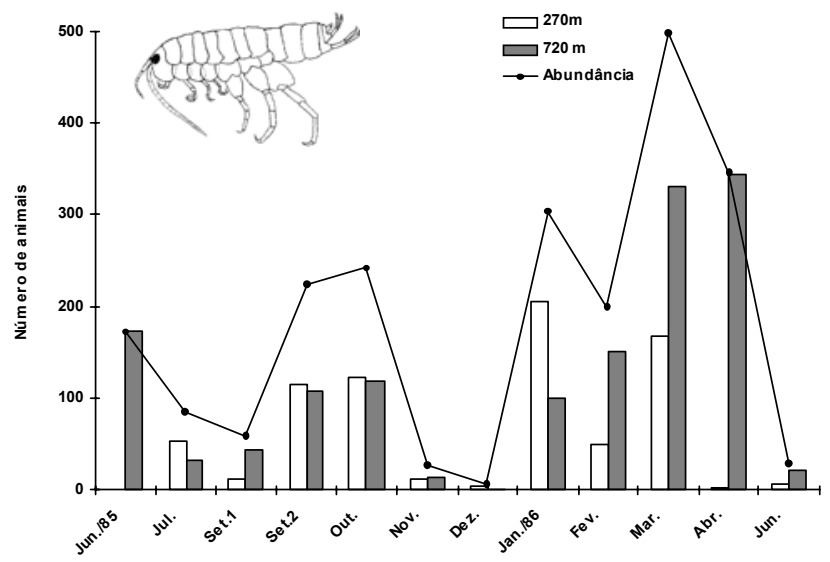

Figura 7. Talitroides topitotum. Flutuação anual da freqüência absoluta da população total (linha) e das ocorrentes a $270 \mathrm{~m}$ (barras verticais vazias) e a $720 \mathrm{~m}$ (barras verticais preenchidas).

A freqüência de exemplares na estação D parece estar correlacionada com a pluviosidade $(r=0,74, p<0,05)$.

Na altitude de $720 \mathrm{~m}$ também foram observados três picos (Fig. 7, Tab. I). O primeiro, de junho/1985 a julho/1985, estaria amostrado de forma parcial, mostrando apenas a área de decréscimo de abundância. O segundo pico, de setembro/1985 a dezembro/1985, tem valores máximos em outubro/1985 com 118 exemplares. No terceiro pico, entre dezembro/1985 e junho/1986, ocorreu apenas um valor máximo em abril/1986 com 344 exemplares. A população que se desenvolve a $270 \mathrm{~m}$ parece ter uma dinâmica diferente daquela que se desenvolve a $720 \mathrm{~m}$.

Na estação A, a maior freqüência ocorreu em outubro/ 1985 quando foram coletados dez exemplares; a freqüência foi

Revista Brasileira de Zoologia 21 (2): 219-227, junho 2004 
nula nesta estação em junho, setembro e dezembro de 1985 , fevereiro e junho de 1986. Na estação B, a maior amostragem ocorreu em julho/1985, com 50 exemplares; nesta estação foi coletado um juvenil em julho/1985; a freqüência foi nula em junho, setembro, novembro e dezembro/1985 e em junho/1986. Na estação C, a coleta de 113 exemplares no final de setembro/ 1985 representou a maior freqüência; a freqüência foi nula em junho, julho e outubro/1985 e em abril e junho/1986. Na estação D, 194 exemplares foram coletados em janeiro/1986; em fevereiro/1986 foram coletados um juvenil e o exemplar que não apresentou caracteres sexuais secundários; a freqüência foi nula em junho, início de setembro, novembro e dezembro/ 1985 e em abril/1986. Os exemplares coletados nas estações A, $\mathrm{B}, \mathrm{C}$ e D parecem mostrar uma mesma dinâmica quanto à freqüência de exemplares. Apesar de diferenças em relação aos meses de ocorrência de picos em cada uma das estações de coleta à altitude de $270 \mathrm{~m}$, a ocorrência de maiores freqüências parece estar relacionada com sazonalidade, sendo maior na primavera e verão, quando as temperaturas médias oscilam entre $20^{\circ} \mathrm{C}$ e $25^{\circ} \mathrm{C}$, com elevada umidade relativa do ar e altos índices de pluviosidade. Em junho/1985 (inverno), a abundância na estação E pode ser explicada pela excepcional temperatura elevada para a estação do ano, em conjunção com a umidade relativa alta. A correlação entre abundância e pluviosidade durante o período de coleta chega a atingir $\mathrm{r}=0,74, \mathrm{p}<0,05$.

$\mathrm{Na}$ estação $\mathrm{E}$, a maior freqüência ocorreu em março/1986; não foram coletados exemplares em julho e dezembro/1985 e em junho/1986. Na estação F, 75 exemplares chegaram a ser coletados em abril/1986, enquanto nos meses de junho, julho, início de setembro e dezembro de 1985 e junho/1986 não foram coletados exemplares. Na estação G, 77 exemplares em março/1986, representaram o maior número de exemplares coletados; neste mês foram coletados quatro juvenis; em setembro, outubro e novembro de 1985 e fevereiro/1986 não foram coletados exemplares. Na estação $H$, a maior coleta, de 44 exemplares, ocorreu em abril/1986 e não foram coletados exemplares no final de setembro e em dezembro de 1985 .

\section{DISCUSSÃO}

A pluviosidade média indicada na série histórica fornecida pela COPEL para a localidade da Usina Hidrelétrica de Guaricana em janeiro é de $311,40 \mathrm{~mm}$, portanto os índices registrados para janeiro/1986 estiveram acima da média (COPEL, relatório interno). Ainda de acordo com a mesma série de dados, a pluviosidade em junho é de $116,90 \mathrm{~mm}$ e em julho, de 128,80 mm; portanto as chuvas de junho/1985 e julho/1985 estiveram bem abaixo da média. O mês indicado como o mais chuvoso é o de janeiro e os mais secos, os de junho e agosto, sendo a pluviosidade anual registrada para a localidade de $2387,50 \mathrm{~mm}$. A pluviosidade registrada no período de estudo esteve abaixo da média em todos os meses, com exceção de janeiro, correspondendo a cerca de $90 \%$ da prevista. T. topitotum foi registrado no México com pluviosidade média mensal de $640 \mathrm{~mm}$ (Alvarez et al. 2000) e no Havaí, onde variou de 1270 $\mathrm{mm}$ a $3800 \mathrm{~mm}$ (RiCHARDSON 1992). Estes dados indicam que $T$. topitotum é uma espécie exigente quanto ao nível de precipitação pluviométrica: valores acima de $105 \mathrm{~mm}$ mensais são necessários para o estabelecimento de suas populações.

Agosto, novembro e dezembro são os meses mais secos do ano no Paraná (MAACK 1968). Os dados de umidade relativa média do ar obtidos em dezembro/1985, 74,04\%, coincidem com a indicação deste mês como o mais seco do período de estudo. Em agosto/1985 não houve coleta, porém no início de setembro/1985 foi registrada a maior umidade relativa do período, 93,0\%. Em novembro/1985 a umidade relativa do ar esteve elevada, 88,38\%. Estes dois últimos meses contrastram com os registros do autor acima.

MAACK (1968) registrou para a Serra do Mar temperaturas mínima de $16,5^{\circ} \mathrm{C}$ e máxima de $27,47^{\circ} \mathrm{C}$. As medições realizadas a $270 \mathrm{~m}$ de altitude apresentam temperaturas altas possivelmente devido à influência de massas de ar quente oriundos da planície litorânea, onde a temperatura média é de $21,1^{\circ} \mathrm{C}$, podendo chegar a $38,0^{\circ} \mathrm{C}$ (MAACK 1968). As temperaturas de $9,0^{\circ} \mathrm{C}$ em junho/1986 e 9, $5^{\circ} \mathrm{C}$ no início de setembro/1985 sugerem que o período de estudo foi excepcionalmente frio.

Sendo T. topitotum um anfípodo que tem preferência pelo substrato solo com serapilheira (Ulian \& Mendes 1987, RichARDSON 1992), a rede Malaise utilizada no presente estudo se mostrou adequada para a captura de fêmeas, mas não de juvenis. Em virtude dessa rede ficar próxima do solo, aliado ao comportamento de saltar destes animais, a sua captura foi possível. Entretanto, devida à fraca capacidade de salto dos juvenis, esse artefato amostrou somente adultos.

Os estudos sobre as altitudes nas quais foram registradas as diversas populações de $T$. topitotum mostram que este parâmetro não é a variável única ou a mais importante na ocorrência e abundância desta espécie. Assim, LAM \& MA (1989) encontraram populações a $120 \mathrm{~m}$ de altitude, RichaRdson (1992) de 316 a $768 \mathrm{~m}$ e Alvarez et al. (2000) a $2475 \mathrm{~m}$. No presente estudo, os $64,85 \%$ do total de anfípodos registrados a $720 \mathrm{~m}$ de altitude parecem estar relacionados mais à qualidade do substrato serapilheira do que às altitudes. Provavelmente, os habitats mais preservados nesta altitude promoveram o estabelecimento de populações mais numerosas.

Entretanto, um certo grau de antropia parece propiciar o desenvolvimento destas populações. Corroboram esta hipótese os resultados de Biernbaum (1980) que, estudando duas populações de T. topitotum, observou uma, com freqüência maior, vivendo próximo e embaixo de residências e barracões e outra, menos numerosa, vivendo em floresta bem conservada ao redor de um lago. A antropia é positiva para propagar esta espécie exótica, porém a excessiva interferência humana sobre a vegetação não favorece grandes populações.

As altas freqüências ocorridas do final de setembro a outubro/1985, e as ainda mais elevadas observadas nas amos-

Revista Brasileira de Zoologia 21 (2): 219-227, junho 2004 
tras de janeiro a março/1986, coincidem com valores mensais de pluviosidade acima de $150 \mathrm{~mm}$. As baixas freqüências ocorridas no início de setembro, em novembro e dezembro/1985 e em junho/1986, não podem ser explicadas apenas com a pluviosidade, apesar desta ter sido coincidentemente reduzida em julho e dezembro/1985.

A umidade média relativa do ar foi baixa em dezembro/ 1985 e um pouco menor que os demais meses em junho/1986, coincidindo com um número reduzido de exemplares coletados. O início de setembro/1985 apresentou a mais alta umidade relativa do ar, entretanto o número de exemplares amostrados foi reduzido. Em laboratório, quando T. topitotum foi colocado em câmara de múltipla escolha para umidade (20 a 28 até $87 \%$ ) a preferência foi sempre pelo compartimento mais úmido (ULIAN \& MeNDEs 1987). Ulian \& MENDEs (1988), observaram ainda que a sobrevivência a $74 \%$ de umidade relativa do ar foi significativamente maior do que em índices inferiores e que a $87 \%$ a sobrevivência era significativamente alta. Os dados encontrados no presente estudo confirmam os obtidos em laboratório.

As temperaturas baixas que ocorreram no início de setembro/1985 e em junho/1986, coincidentes com baixas freqüências de exemplares coletados, sugerem que este fator tenha influência sobre a atividade dos animais. As temperaturas elevadas, acima de $35^{\circ} \mathrm{C}$, que ocorreram em dezembro/1985 parecem ter reduzido a população neste mês; entretanto, o mesmo não ocorreu no mês de fevereiro/1986, quando foi verificada uma freqüência alta. Em experimento de laboratório em pista de gradiente térmico $\left(13\right.$ a $\left.30^{\circ} \mathrm{C}\right)$, T. topitotum preferiu as temperaturas de $20^{\circ} \mathrm{C}$ a $26^{\circ} \mathrm{C}$ e áreas mais quentes foram mais evitadas que as frias (Ulian \& Mendes 1987). A homeostase respiratória ocorre de $25^{\circ} \mathrm{C} \mathrm{a} 30^{\circ} \mathrm{C}$ (Mendes \& Ulian 1987). Os dados sugerem que o fator temperatura atua de modo integrado com as demais variáveis e não explica de forma isolada o comportamento da espécie.

Uma análise em conjunto das estações em ambas as altitudes mostra que a abundância destes animais está relacionada com a conjunção de temperaturas do ar acima de $16^{\circ} \mathrm{C}$ e umidade relativa do ar acima de $80 \%$. Assim, em dezembro, apesar da temperatura favorável (média em torno de $25^{\circ} \mathrm{C}$ ), a umidade relativa do ar esteve em torno de $75 \%$, o que fez cair a abundância para os níveis de menos de 50 indivíduos. Os baixos valores de abundância registrados em julho/1985, início de setembro/1985 e junho/1986 podem ser explicados pelas temperaturas médias abaixo de $16^{\circ} \mathrm{C}$, apesar dos altos índices de umidade relativa registrados nestes meses. O fato de poucos animais terem sido registrados em novembro é de difícil interpretação, pois tanto a temperatura do ar como a umidade relativa do ar tiveram valores favoráveis ao desenvolvimento desta população.

A interação entre os efeitos da pluviosidade, da umidade relativa do ar e da temperatura do ar determina a abundância das populações de T. topitotum. Altos valores de pluviosidade e de umidade relativa do ar estimulam a atividade desta espécie, possibilitando a sua captura com rede de Malaise. Por outro lado, tanto valores abaixo de $13^{\circ} \mathrm{C}$, quanto valores acima de $35^{\circ} \mathrm{C}$, limitam a atividade destes anfípodos.

\section{AGRADECIMENTOS}

Ao CNPq pela bolsa de Mestrado conferida à primeira autora. Ao Dr. Charles K. Biernbaum da Grice Marine Laboratory, College University of Charleston, pelas informações acerca dos caracteres secundários masculinos de Talitroides topitotum. À Dra Janete Dubiaski da Silva da Pontífica Universidade Católica do Paraná, pela leitura crítica do manuscrito, especialmente no que concerne à análise estatística. Este artigo é parte da dissertação de mestrado defendida no Curso de Pós-Graduação em Zoologia, UFPR, cujos coordenadores são efusivamente agradecidos.

\section{REFERÊNCIAS BIBLIOGRÁFICAS}

Alvarez, F.; I. Winfield \& S. Cházaro. 2000. Population study of the landhopper Talitroides topitotum (Crustacea: Amphipoda: Talitridae) in central Mexico. Journal of Natural History, London, 34: 1619-1624.

Biernbaum, C.K. 1980. Occurrence of the "tramp" terrestrial amphipods Talitroides alluaudi (Chevreux) and T. topitotum (Burt) (Amphipoda: Talitridae) in South Carolina. Brimleyana, Raleigh, 3: 107-111.

Bousfield, E.L. 1960. New records of beach hoppers (Crustacea: Amphipoda) from the coast of California. Bulletin of National Museum of Canada, Ottawa, 172: 1-12.

. 1982. The amphipod Superfamily Talitroidea in the Northeastern Pacific region. I. Family Talitridae: systematics and distributional ecology. National Museum of Natural Science Publications in Biological Oceanography, Ottawa, 11: 1-73.

BurT, D.R.R. 1934. On the amphipod genus Talitrus, with a description of a new species from Ceylon, Tatitrus (Talitropsis) topitotum, sub-gen. et sp. nov. Ceylon Journal Science, Peradeniya, 18 (2): 181-193.

Lemos de Castro, A. 1972. Talitrus (Talitroides) pacificus Hurley, anfípodo terrestre introduzido em São Paulo. Arquivos do Instituto Biológico São Paulo, São Paulo, 39 (3): 201-203.

Lemos de Castro, A. \& V.F.G. Pereira. 1978. Anfípodos terrestres do gênero Talitrus introduzidos no Brasil (Amphipoda, Talitridae). Atas da Sociedade Biológica do Rio de Janeiro, Rio de Janeiro, 19: 47-49.

Friend, J.A. \& A.M.M. Richardson. 1986. Biology of terrestrial amphipods. Annual Review of Entomology, Palo Alto, 31: $25-48$.

IвGE. 1992. Manual técnico da vegetação brasileira. Rio de Janeiro, Fundação Instituto Brasileiro de Geografia e Estatística, Série Manuais Técnicos em Geociências, 92p.

LAM, P.K.S. \& H.H.T. MA. 1989. Some observations on the cycle and population dynamics of Talitroides topitotum (Burt)

Revista Brasileira de Zoologia 21 (2): 219-227, junho 2004 
(Amphipoda; Talitridae) in Hong Kong. Journal of Natural History, London, 23: 1087-1092.

MAAск, R. 1968. Geografia física do Estado do Paraná. Curitiba, Max Roesner, 350p.

Mendes, E.G. \& G.B. Ulian. 1987. The influence of size, temperature and oxigen tension upon the respiratory metabolism of the terrestrial amphipod Talitrus (Talitroides) pacificus, Hurley, 1955. Comparative Biochemistry and Physiology, New York, 86 (1): 155-162.

MorritT, D. 1998. Hygrokinetic responses of talitrid amphipods. Journal of Crustacean Biology, Lawrence, 18 (1): 25-35.

RiCHARDSON, A.M.M. 1992. Altitudinal distribution of native and alien landhoppers (Amphipoda: Talitridae) in the Ko'olau
Range, O'ahu, Hawaiian Islands. Journal of Natural History, London, 26: 339-352.

Rizzinı, C.T. 1979. Tratado de fitogeografia do Brasil: aspectos sociológicos e florísticos. São Paulo, Universidade de São Paulo, Hucitec, 374p.

Ulian, G.B. \& E.G. Mendes. 1987. Preferences of a terrestrial amphipod, Talitrus (Talitroides) pacificus, Hurley, 1955, towards some environmental factors. Revista Brasileira de Biologia, Rio de Janeiro, 47 (3): 247-256.

. 1988. Tolerances of a land amphipod, Talitrus (Talitroides) pacificus Hurley, 1955, towards temperature and humidity variations and immersion in water. Revista Brasileira de Biologia, Rio de Janeiro, 48 (2): 179-187.

Recebido em 16.V.2003; aceito em 05.V.2004.

Revista Brasileira de Zoologia 21 (2): 219-227, junho 2004 